6-1-2014

\title{
Investigating the impact of television advertisement image quality on telepresence, attitude towards brands and purchase intentions
}

Cheryl C. Bracken

Cleveland State University, c.bracken@csuohio.edu

Follow this and additional works at: https://engagedscholarship.csuohio.edu/clcom_facpub

Part of the Communication Commons

How does access to this work benefit you? Let us know!

\section{Recommended Citation}

Bracken, C. C. (2014). Investigating the impact of television advertisement image quality on telepresence, attitude towards brands and purchase intentions. International Journal of Digital Television, 5(2), 137-147. https://doi.org/10.1386/jdtv.5.2.137_1

This Article is brought to you for free and open access by the School of Communication at EngagedScholarship@CSU. It has been accepted for inclusion in Communication Faculty Publications by an authorized administrator of EngagedScholarship@CSU. For more information, please contact library.es@csuohio.edu. 


\title{
Investigating the impact of television advertisement
} image quality on telepresence, attitude towards brands and purchase intentions

\begin{abstract}
In an experiment manipulating the image quality of television ads, 127 participants watched television commercials in either high or low image quality. The participants rated each ad for their attitude towards the ad and purchase intentions. Additionally, sensations of telepresence and transportation were assessed. The participants who viewed the ads in higher image quality reported more positive attitudes towards the brands, and higher levels of telepresence. The implications are discussed.
\end{abstract}

\section{INTRODUCTION}

Around the world, television broadcast has been converting from analogue to digital with higher image quality presentations. While most countries are now broadcasting in digital, not everyone is watching television content 
in High Definition (HD). Audiences are watching the same content in differing image quality. This article investigates how viewing commercials in differing image quality may impact audience responses to the brands featured in the advertisement. In the current study, participants' ${ }^{\prime}$ sensations of telepresence, attitude towards the ad, and purchase intentions are assessed after viewing a series of television advertisements in either high or low image quality.

\section{TELEPRESENCE}

Telepresence is generally accepted as is 'the perceptual illusion of nonmediation' (Lombard and Ditton 1997, par. 2). Common perception is that the concept originated within the field of computer science and was intended to describe the phenomenon of tele-robotics in the 1980s. However, Cianci presents evidence that NHK was experimenting with television in the 1960s in an attempt to 'induce a sensation of reality' (2012: 14) a sensation at the heart of the concept of telepresence.

The concept of telepresence was introduced to the field of Communication by Steuer (1992). Even though telepresence has originated within virtual reality and other mediated environments, it has been established that television viewers also experience a sense of telepresence - viewers respond to objects and people on the screen as if they were real (Lombard et al. 2000). Early work by Ohgushi et al. (1993) identified that image quality could impact both physical and psychological factors (and specifically telepresence) in television viewers. Further links were found by Kim and Biocca (1997) and Lombard et al. (2000). Recent work on entertainment media (e.g., television, mobile media, video games, etc...) has led to telepresence being defined as a psychological state where the media technology becomes transparent allowing for media users to suspend the experience of mediation (Bracken et al. 2010; Pettey et al. 2010).

\section{Telepresence and entertainment media}

While the bulk of telepresence research has focused on the creation of and media users' responses to highly immersive environments (Bystrom et al. 1999; Mania and Chalmers 2001; Schubert et al. 2001; Slater et al. 2000), there are some researchers who have studied entertainment media. The use of media to induce telepresence-like experiences is not a new phenomenon. For a detailed discussion of telepresence and media history, see IJsselsteijn (2003).

Other entertainment media and telepresence researchers have found that television audiences have telepresence experiences (Lombard et al. 2000) and film-makers intentionally encourage audiences to 'stay in the film' (Marsh 2003; Neuendorf and Lieberman 2010). While, research on video games has shown telepresence is not only experienced by video game players (Bracken, Skalski, and Tamborini 2005; Lee 2005) but some researchers have argued telepresence should be considered a moderating variable in studying game play (Bracken and Skalski 2010). Taken together these findings demonstrate that telepresence is experienced by media users in less immersive (than virtual reality) popular media environments. This article further explores the possibilities of telepresence and television with particular attention to the impact of image quality. The following section will detail what is known to date about telepresence and entertainment media. 


\section{Encouraging telepresence in entertainment media}

Researchers in the area of entertainment and telepresence have identified variables likely to encourage telepresence sensations - these include both form and content variables. Form variables as known as structural features are elements of audio-visual presentations that include cuts, edits, camera movements, etc.... Two types of form variables were identified: producer controlled and user controlled (Lombard and Ditton 1997).

\section{Producer-controlled structural features}

Producer-controlled structural features are controlled by the producer of the content are aspects of the presentation that are determined prior to exhibition or distribution. Examples include pace, camera shots and cuts. There are fewer studies exploring this type of form variable and telepresence. However, the literature suggests that faster, quick cutting programmes decrease a media users' sense of telepresence (Bracken and Pettey 2007). Producer-controlled variables have been more widely studied with video games. Video games have also been found to evoke a sense of telepresence (Eastin et al. 2005).

Television commercials contain a wide variety of producer-controlled variables. There a significant body of research that demonstrates the audiences are impacted by changes in producer controller variables such as pace (Grabe et al. 2003; Lang et al. 2007; Wise et al. 2008). However, there has been little attention given to changes in user-controlled structural features which is the primary concern of the current study.

\section{User-controlled structural features}

Structural features that can be controlled by media users to adjust the presentation or delivery of the media experience are user-controlled variables. These variables include media technologies that can be purchased to enhance viewing experiences. Examples of user-controlled variables are screen size, surround sound and image quality. Findings related to user-controlled variables demonstrate that larger screen size (or field of view (FOV)) (Bracken and Atkin 2004; IJsselsteijn et al. 2001), improved quality of both the sound (Lessiter et al. 2001) and the image quality (Bracken 2005; Bracken and Botta 2010) increase the likelihood that the media user will experience a sense of telepresence. Similar findings were documented with increased image quality and video games (Bracken and Skalski 2009).

Based on previous research findings, the following hypotheses are posited:

H1: Participants who watch higher image quality commercials will report higher levels of telepresence than participants who watch lower image quality television commercials.

\section{Telepresence and persuasion}

There are only a few studies exploring the impact of telepresence on persuasion (Grigorovici 2003; Kim and Biocca 1997; Li et al. 2002; Skalski and Tamborini 2005). An explanation for why telepresence should increase advertising effectiveness is offered by Lombard and Synder-Duch who state

One thing interactivity is thought to increase is the sense of 'presence,' and presence is thought to lead to a variety of effects which include 
enjoyment and persuasion, primary goals of advertising. Therefore presence, and research and theory concerning presence, may serve as a useful guide to understanding and marshaling the use of interactivity in advertising to maximum effect.

(2001, par. 18)

\section{Telepresence and purchase intentions}

Telepresence has been found to impact persuasion in less immersive environments. Specifically, Kim and Biocca (1997) found that higher sensations of spatial presence led to higher purchase intentions and consumer confidence. In a series of experiments exploring the role of presence on consumers' responses to 3D advertising, researchers ( $\mathrm{Li}$ et al. 2002) found that telepresence influenced consumers' feeling of physical presence and engagement, and higher purchase intentions.

\section{Telepresence and attitude towards the brand}

The impact of telepresence on attitudes has not been widely studied. One study that examined sensations of telepresence and attitudes towards online advertising found that higher levels of telepresence lead to more positive attitudes towards both the brand and the ad overall (Hopkins et al. 2004). Thus, the following hypothesis is put forth:

The literature reviewed here suggests that media audiences that view higher image quality images are impacted by what they are viewing. Thus the following hypotheses are posited:

H2: Participants who watch higher image quality commercials will report more positive attitude towards the brands (in the commercials) than participants who watch the lower image quality commercials.

H3: Participants who watch higher image quality commercials will report more positive purchase intentions (of the brands in the commercials) than participants who watch the lower image quality commercials.

Additionally, to better understand the role of telepresence and its potential uses with persuasive messages the role of telepresence will be tested to see if it has any impact on attitudes towards the brands in the advertisements and purchase intentions.

$\mathrm{RQ1}$ : Do participants who reported higher levels of telepresence report more positive attitudes towards the brand?

RQ2: Do participants who reported higher levels of telepresence report higher purchase intentions.

\section{METHOD}

A total of 127 participants watched television advertisements either in higher image quality (HD - 1080i lines) or lower image quality (SD - 480i lines). The experimental design was between participant and half the participants watched television commercials in higher image quality $(n=61)$ and the others watched lower image quality television commercials $(n=67)$. 


\section{Participants}

The 127 participants who participated in the experiment were between 18 and 41 years old $(M=20.25, S D=4.01)$. The vast majority were between the ages of 18 and 21. There were 65 females and 62 males. A total of $52 \%$ of the participants reported being Caucasian, 32\% African American, 6.4\% Hispanic, 4.8\% Asian and $4.8 \%$ other.

\section{Stimulus}

All the participants watched three commercials. Each commercial was 30 seconds in length. The three commercials represented difference product types. The commercials were for Budweiser beer, Federal Express and Nextel mobile phones. All of these Brands were known to the participants and are products they will have encountered in their daily lives.

\section{Independent variables}

\section{Image Quality}

The image quality of the television commercials was manipulated with one group watching the commercials in higher image quality or HD (HD - 1080i) and the other group watching the commercials in lower image quality (SD - 480i).

\section{Dependent variables}

\section{Telepresence}

Since telepresence is a multi-dimensional concept, the current study includes two separate sub-dimension measures that are the most appropriate for low immersive media (Bracken and Skalski 2010).

\section{Immersion}

This dependent variable was measure using five items developed by Lombard et al. (2009). The participants were asked to respond to items enquiring about how engaged, immersed and involved they were in the commercials. Examples of the items included: 'To what extent did you feel mentally immersed?', 'How involving was the experience?' and 'How completely were your senses engages?'. The Chronbach's $\alpha$ was 0.89 .

\section{Spatial presence}

This variable was measure using three items developed by Lombard, Ditton, and Weinstein (2009). This dimension of presence is sometimes called physical presence and examines how much a part of the action the participants felt. Examples included: 'How much did it seem as if the objects and people you saw/heard had come to the place you were?', and 'To what extent did you experience a sense of being there inside the environment you saw/heard?'. The Chronbach's $\alpha$ was 0.86

\section{Attitude towards the brand}

Attitude towards the brand name (Schmilt et al. 1994) was measured using a six-item, seven-point Semantic Differentials ( $1=$ Strongly Disagree to $7=$ Strongly agree) that summarized the respondents' feelings towards the 
brand names within the individual ads. Examples included 'Dislike/Like', 'Negative/Positive' and 'Bad/Good'. The Chronbach's $\alpha$ was 0.96 .

\section{Purchase intention}

Purchase Intention was measured using the purchase intentions scale (Ford and LaTour 1993). This scale included five items that measured purchase intention of participants using a seven-point Likert scale (1=Strongly agree to $7=$ Strongly disagree). Examples include: 'If a new product is introduced with ads that I find offensive, I might still buy it if it offers me benefits I find attractive' and 'If a new product or service which I use adopts an ad campaign which I find offensive, I'll discontinue using it'. The Chronbach's $\alpha$ was 0.96 .

\section{Procedure}

The participants assigned randomly to either to higher or lower image quality condition. The participants watched the commercials in a group setting on a large screen (162-inch or 411-centimetre screen measured diagonally). The order of the commercials was varied to control for order effects. Once they were seated, the researcher started the commercials. The experimenter instructed the participants to watch each commercial and then to answer the appropriate section of the pencil-and-paper questionnaire. The questionnaire included additional instructions for the participants to either continue on to the next page of to stop and wait for the next commercial to play. The entire experiment was completed in 25 minutes.

\section{ANALYSIS AND RESULTS}

All of the hypotheses and the research questions were analysed using $t$-Tests to compare the two different groups (e.g. high vs low image quality). The results are as follows:

Hypothesis 1 predicted that commercials viewed in higher image quality would result in higher sensations of telepresence. H1 was supported $(t=-3.50, \mathrm{df}=126, p=0.001)$ for immersion and for spatial presence $(t=-3.45$, $\mathrm{df}=126, p=0.001$ ). Participants who viewed the higher image quality commercials reported higher levels of immersion $(M=3.32 ; \mathrm{SD}=1.10)$ than those who viewed the lower image quality commercials $(M=2.59 ; \mathrm{SD}=1.23)$. Likewise, participants who watched the higher image quality commercials reported more sensations of spatial presence $(M=2.98, \mathrm{SD}=1.150)$ than the participants who watched the lower image quality commercials $(M=2.28, \mathrm{SD}=1.13)$.

Participants who watched higher image quality commercials were predicted to report more positive attitudes towards the brand. This hypothesis $(\mathrm{H} 2)$ was supported $(t=3.47, \mathrm{df}=126, p=0.001)$. Viewing the higher image quality commercials resulted in more positive attitudes $(M=3.84, \mathrm{SD}=1.19)$ than viewing the lower quality commercials $(M=3.09, \mathrm{SD}=1.27)$. However, Hypothesis 3 that predicted viewing higher image quality would lead to higher purchase intentions was not supported $(t=-6.00, \mathrm{df}=126, p=0.545)$.

In an attempt to better understand the role of telepresence in the process of persuasion, research questions were posed asking about the relationship between levels of telepresence experienced and audiences' attitudes and purchase intentions. Both dimensions of telepresence (immersion and spatial presence) were tested using $t$-Tests. Two groups were created to allow for the analyses to be conducted. Specifically, immersion was split into high and low 
groups using the mean. Similarly, two levels of spatial presence were created by splitting the participants into a high group and low group using a mean split.

Participants who reported higher levels of immersion reported significantly $(t=5.02, \mathrm{df}=126, p=0.001)$ more positive attitudes towards the brand $(M=4.39$, $\mathrm{SD}=1.00)$ than participants who reported lower levels of immersion $(M=3.08$, $\mathrm{SD}=1.03$ ). Higher levels of immersion also resulted in significantly higher purchase intentions ( $t=-4.49, \mathrm{df}=126, p=0.001$ ) with participants who reported higher levels of immersion also reported higher purchase intention $(M=3.64, \mathrm{SD}=1.13)$ than those who reported lower levels of immersion $(M=2.45, \mathrm{SD}=0.89)$.

The results for the $t$-Test for spatial presence yielded similar results. Participants who reported higher levels of spatial presence reported significantly $(t=-4.12, \mathrm{df}=126, p=0.001)$ more positive attitudes towards the brand $(M=4.40, \mathrm{SD}=1.05)$ than participants who reported lower levels of spatial presence $(M=3.29, \mathrm{SD}=1.07)$. Additionally, higher reported levels of spatial presence led to significant differences in purchase intentions $(t=-3.41, \mathrm{df}=126$, $p=0.001)$. Participants who reported higher levels of spatial presence also reported higher purchase intentions $(M=3.62, \mathrm{SD}=1.09)$ than participants who reported lower levels of spatial presence $(M=2.68, \mathrm{SD}=1.05)$.

\section{DISCUSSION}

The overall results of this study demonstrate that higher image quality commercials are more potentially effective than lower image quality commercials. Specifically, the higher image quality commercials were reported to illicit stronger sensations of telepresence - both immersion and spatial presence. These findings are consistent with the predictions based on the telepresence literature and are consistent results reported by Bracken (2005) and Bracken and Botta (2010). However, the comparison of higher and lower image quality of television commercials had not been undertaken previously and the results suggest important outcomes that both practitioners and researchers should consider. For example, current technology allows users to select the image quality of streaming videos online. If the media audience member selects a lower image quality (for whatever reason) it may impact how positively they respond to message - regardless of the content of the message.

The current results also support prior research on telepresence and persuasionspecifically the attitudes towards the brand (Hopkins et al. 2004) and purchase intensions (Kim and Biocca 1997). The theoretical implications of this study include the use of telepresence as a concept that has potential for persuasion. This study also extends our knowledge telepresence responses to popular media. The results are significant because it is one of the shortest audio/visual exposures (30 seconds) demonstrated to elicit a sense of telepresence in audiences. Further, the results contribute to our knowledge about user-controlled structural features. In the past, image quality had been seen a structural feature that may influence enjoyment but not as playing a role on the creation of attitudes towards a product or brand or even more dramatic, the prediction of future behaviours.

The differences in reported attitudes towards the brand based only on exposure to either high or low image quality has far reaching implications. Advertisers may want to invest in the additional expense for advertisement in higher image quality for certain brands to ensure that audiences view their commercials in the higher image quality available to the media user. This, of course, it somewhat problematic and is influenced by a number of factors including whether or not the commercial is being watch via broadcast 
or cable, or streamed over the Internet, which then is impacted by Internet speed and mobile phone data plans. Additionally, this result is consistent with an earlier study that found higher quality images lead to more positive evaluations of television content (Bracken 2006). Audiences seem to respond more positively to content aired in higher image quality. This result should be received positively by advertisers who have been looking for ways to reach television viewers.

These results demonstrated not only that image quality can impact audience attitudes but participants who viewed the television commercials in higher image quality also reported significantly higher levels of purchase intentions of the products seen in the commercials.

Hypothesis 3 that predicted a positive relationship between higher image quality and intended purchase intentions was not supported. Given the support found for the other hypotheses and significant findings for the other research questions, it is not clear why this is so. It may be that most that the range of product types- selected to appeal to this particular group - did not provide enough product or brand range to find differences. However, higher levels of both telepresence sub-dimensions (e.g. immersion and spatial presence) were found to increase the likelihood of purchasing and suggesting possible interactions between these independent variables.

\section{Limitations}

Like all studies, the current experiment has limitations. It should be noted that the participants were exposed to only three commercials. This is a relatively small number compared to the number of ad seen daily by media users. While the research attempted to provide a variety of brand types not all categories were represented. Additionally, the participants of the current study were mostly young adults who may report purchase intentions which in reality are limited by their income levels.

The current study also did not adhere to the screen size and preferred viewing distance prescribed by the International Telecommunication Union (2012). Specifically, the image viewed by the participants was presented on a162-inch or 411-centimetre screen measured diagonally and the FOV was ranged from a narrow FOV $\left(14.8^{\circ}\right)$ to a wide FOV $\left(53.1^{\circ}\right)$ (Collins 2011). The recommended FOV is more than $30^{\circ}$. The actual distance that participants sat from the screen ranged from 14 to 55 feet ( 4.26 to 16.76 metres). It should be noted that prior research on the impact of $\mathrm{HD}$ and presence found that presence can be impacted by a wider FOV (Bracken 2006).

\section{Future research}

The findings of the current study suggest several avenues of research for the future. With the increase of streaming video viewing over the Internet, one possibility is to compare audience responses to differing image quality of Internet-based content such as watching videos on YouTube where viewers can select the image quality.

Another area worth exploring is the possible interactions between image quality, telepresence and purchase intentions. Studies should be designed to with additional product categories to allow for a broader comparison. Other types of non-entertainment content should be tested. Perhaps viewing public service announcements (PSAs) in higher image qualities may result in more positive behavioural changes. 
Additional avenues of research include exploring the impact of varying screen sizes especially larger than the average $\left(30^{\prime} \times 70^{\prime}[9.1 \times 21\right.$ metres]) to best benefit from the HD image quality.

In conclusion, image quality influences audiences' perceptions of television commercials. Higher image quality increased reported sensations of telepresence, attitudes towards the brand featured in the commercial and purchase intentions. The results of the current study contribute to both the telepresence and Advertising literatures by demonstrating the role of varying image quality.

\section{REFERENCES}

Bracken, C. C. (2005), 'Presence and image quality: The case of High Definition television', Media Psychology, 7: 2, pp. 191-205.

(2006), 'Perceived source credibility of local television news: The impact of television form and presence', Journal of Broadcasting E Electronic Media, 50: 4, pp. 723-41.

Bracken, C. C. and Atkin, D. (2004), 'How screen size affects perception of television: A survey of presence-evoking technology in our living rooms', Visual Communication Quarterly, 59: 4, pp. 23-28.

Bracken, C. C. and Botta, R. (2010), 'Telepresence and television', in C. C. Bracken and P. D. Skalski (eds), Immersed in Media: Telepresence and Everyday Life, New York: Routledge, pp. 39-62.

Bracken, C. C. and Pettey, G. (2007), 'It is REALLY a smaller (and smaller) world: Presence and small screens', Proceedings of the Tenth Annual International Meeting of the Presence Workshop, Barcelona, Spain: ISPR, pp. 283-290.

Bracken, C. C. and Skalski, P. (2009), 'Presence and video games: The impact of image quality', PsychNology, 7: 1, pp. 101-12.

(2010), 'Telepresence in everyday life: An introduction', in C. C. Bracken and P. D. Skalski (eds), Immersed in Media: Telepresence and Everyday Life, New York: Routledge, pp. 3-8.

Bracken, C. C., Pettey, G., Guha, T. and Rubenking, B. E. (2010), 'Sounding out small screens and telepresence: The impact of audio, screen size, and pace', Journal of Media Psychology: Theories, Methods, and Applications, 22: 3, pp. 125-37.

Bystrom, K. E., Barfield, W. and Hendrix, C. (1999), 'A conceptual model of the sense of presence in virtual environments', Presence: Teleoperators $\mathcal{E}$ Virtual Environments, 8: 2, pp. 241-45.

Cianci, P. J. (2012), High Definition Television: The Creation, Development and Implementation of HDTV Technology, Jefferson, NC: McFarland.

Collins, C. M. (2011), 'Viewing distance calculator', http://www.myhometheater.homestead.com/viewingdistancecalculator.html. Accessed 8 June 2014.

Eastin, M. S., Griffiths, R. and Lerch, J. (2005, May), 'Beyond shooter games: How game environment, game type, and competitor influence presence, arousal and aggression', paper presented to the Communication \& Technology Division of the Annual International Communication Association, New York.

Ford, J. B. and LaTour, M. S. (1993), 'Differing reactions to female role portrayals in advertising', Journal of Advertising Research, 33: 5, pp. 43-52.

Gerrig, R. J. (1993), Experiencing Narrative Worlds, New Haven, CT: Yale University Press.

Grabe, M., Lang, A. and Xiaoquan, Z. (2003), 'News content and form', Communication Research, 30: 4, pp. 387-413. 
Grigorovici, D. (2003), 'Persuasive effects of presence in immersive virtual environments', in G. Riva, F. Davide and W. IJsselsteijn (eds), Being There: Concepts, Effects, and Measurement of Presence in Synthetic Environments, Amsterdam: Ios Press, pp. 192-207.

Hopkins, C. D., Raymond, M. A. and Mitra, A. A. (2004), 'Consumer responses to perceived telepresence in the online advertising environment: The moderating role of involvement', Marketing Theory, 4: 1-2, pp. 137-62.

IJsselsteijn, W. (2003). 'Presence in the past: What can we learn from media history?', in G. Riva, F. Davide and W. IJsselsteijn (eds), Being There: Concepts, Effects, and Measurement of Presence in Synthetic Environments, Amsterdam: Ios Press, pp. 18-40.

IJsselsteijn, W., de Ridder, H., Freeman, J., Avons, S. E. and Bouwhuis, D. (2001), 'Effects of stereoscopic presentation, image motion, and screen size on subjective and objective corroborative measures of presence', Presence: Teleoperators \& Virtual Environments, 10: 3, pp. 298-312.

International Telecommunication Union (2012), Recommendation ITU-R BT.500-13 Methodology for the Subjective Assessment of the Quality of Television Pictures (Electronic Publication), Geneva, Switzerland: ITU.

Kim, T. and Biocca, F. (1997), 'Telepresence via television: Two dimensions of telepresence may have different connections to memory and persuasion', Journal of Computer-Mediated Communication, 3: 2. Retrieved on July 7,2014 from http://onlinelibrary.wiley.com/enhanced/doi/10.1111/j.10836101.1997.tb00073.x/

Lang, A., Park, B., Sanders-Jackson, A. N., Wilson, B. D. and Zheng, W. (2007), 'Cognition and emotion in TV message processing: How valence, arousing content, structural complexity, and information density affect the availability of cognitive resources', Media Psychology, 10: 3, pp. 317-38.

Lee, K. M. (2005, May), 'Presence as a mediator for psychological effects of computer games', paper presented to the Communication \& Technology Division of the Annual International Communication Association, New York.

Lessiter, J., Freeman, J. and Davidoff, J. (2001. May), 'Really hear? The effects of audio quality on presence', paper presented to the PRESENCE 2001: The Fourth Annual Workshop on Presence, Philadelphia, PA.

Li, H., Daugherty, T. and Biocca, F. (2002), 'Impact of 3-D advertising on product knowledge, brand attitude, and purchase intention: The mediating role of presence', Journal of Advertising, 31: 3, pp. 43-57.

Lombard, M. and Ditton, T. B. (1997), 'At the heart of it all: The concept of presence', Journal of Computer-Mediated Communication, 13: 3.Retrieved on July 7, 2014 from http://onlinelibrary.wiley.com/enhanced/doi/10.1111/ j.1083-6101.1997.tb00072.x/

Lombard, M. and Snyder-Duch, J. (2001), 'Interactive advertising and presence: A framework', Journal of Interactive Advertising, 1: 2, 56-65.

Lombard, M., Ditton, T. B. and Weinstein, L. (2009, November). 'Measuring (tele)presence: The temple presence inventory', presented at the PRESENCE 2009: The Twelfth International Workshop on Presence, Los Angeles, California, USA.

Lombard, M., Reich, R. D., Grabe, M. E., Bracken, C. C. and Ditton, T. B. (2000), 'Presence and television: The role of screen size', Human Communication Research, 26: 1, pp. 75-98.

Mania, K. and Chalmers, A. (2001), 'The effects of levels of immersion on memory and presence in virtual environments: A reality centered approach', CyberPsychology \& Behavior, 4: 2, pp. 247-65. 
Marsh, T. (2003), 'Presence as experience: Film informing ways of staying there', Presence: Teleoperators \& Virtual Enoironments, 12: 5, pp. 538-49.

Neuendorf, K. A. and Lieberman, E. (2010), 'Film: The original immersive medium', in C. C. Bracken and P. D. Skalski (eds), Immersed in Media: Telepresence and Everyday Life, New York: Routledge, pp. 9-38.

Ohgushi, K., Kumada, J., Nishizawa, T. and Mitsuhashi, T. (1993), 'hi-vision standards', in NHK Science and Technical Research Laboratories (ed.), High Definition Television: Hi-Vision Technology, New York: Springer, pp. 1-36.

Pettey, G., Bracken, C. C., Rubenking, B., Buncher, M and Gress, E. (2010), 'Telepresence, soundscapes and technological expectation: Putting the Observer into the equation', Virtual Reality, 14: 1, pp. 15-25.

Schmitt, B., Pan, Y. and Tavassoli, N. (1994), 'Language and consumer memory: The impact of linguistic differences between Chinese and English', Jourmal of Consumer Research, 21: 3, pp. 419-31.

Schubert, T., Friedmann, F. and Regenbrecht, H. (2001), "The experience of presence: Factor analytic insights', Presence: Teleoperators \& Virtual Environments, 10: 3, pp. 266-82.

Slater, M., Sadagic, A., Usoh, M. and Schroeder, R. (2000), 'Small-group behavior in a virtual and real environment: A comparative study', Presence: Teleoperators \& Virtual Environments, 9: 1, pp. 37-52.

Skalski, P. and Tamborini, R. (2005, May), 'Vividness, social presence, and persuasion: Reconsidering the influence of modality on attitude formation', Paper presented to the Information Systems Division of the Annual International Communication Association, New York.

Steuer, J. (1992), 'Defining virtual reality: Dimensions determining telepresence', Journal of Communication, 42: 4, pp. 73-93.

Wise, K., Lee, S., Lang, A., Fox, J. R. and Grabe, M. (2008), 'Responding to Change on TV: How viewer-controlled changes in content differ from programmed changes in content', Journal of Broadcasting \& Electronic Media, 52: 2, pp. 182-99.

\section{SUGGESTED CITATION}

Bracken, C. C. (2014), 'Investigating the impact of television advertisement image quality of on telepresence, attitude towards brands and purchase intentions', International Journal of Digital Television 5: 2, pp. 137-147, doi: $10.1386 / j d t v .5 .2 .137 \_1$

\section{CONTRIBUTOR DETAILS}

Dr Cheryl Campanella Bracken is a Professor in School of Communication at Cleveland State University in Cleveland, $\mathrm{OH}$, USA. Her research interests include psychological processing of media. Specifically she is interested in telepresence and the impact of media form variables (i.e., image quality and screen size) on audiences' perceptions of media content. Dr Bracken is the co-editor of the only book focused on popular media and telepresence entitled Immersed in Media: Telepresence in Everyday Life.

E-mail: c.bracken@csuohio.edu

Cheryl Campanella Bracken has asserted her right under the Copyright, Designs and Patents Act, 1988, to be identified as the author of this work in the format that was submitted to Intellect Ltd. 